\title{
Investigating Collaborative Interdisciplinary Practice to Develop a New Planning Undergraduate Course
}

\author{
Planning, Practice \& Research. 34 (2), 225-238
}

\begin{abstract}
Whilst there is widespread recognition of the importance of university education preparing planners for working in interdisciplinary environments, there is limited research available on interdisciplinary working in practice. As detailed knowledge of practice and continuing engagement with practitioners is important to ensuring the employability of graduates, a study of interdisciplinary collaborative practice was undertaken to help develop a new undergraduate planning course. This paper presents the findings of this research and discusses how they will inform the development of the course.
\end{abstract}

Key words: interdisciplinary practice, employability, planning education

\section{Author: Suzy Nelson, School of Architecture and Cities, University of Westminster, London, UK}

Corresponding Author: Suzy Nelson, e-mail: .nelsons@westminster.ac.uk.

\section{Introduction}

Interdisciplinarity is widely advocated by academics and policy makers, but there is little research on interdisciplinary practice in the planning of the built environment. As there is an increasing emphasis on the employability of graduates, it is important that the design of university courses is informed by knowledge of current practice. This paper reports on a study of collaborative interdisciplinary practice, which aims to make a contribution to addressing the gap in knowledge about interdisciplinary practice in order to develop a new undergraduate planning course aimed at educating design literate planners, who will be able to work effectively in interdisciplinary teams. The paper begins with a review of academic and policy literature advocating interdisciplinary approaches to tackle challenging real world problems. It then outlines interdisciplinary built environment educational initiatives in the UK and discusses the need to engage with a community of practice to promote the employability of graduates. Existing literature on the practice of built environment professions in the UK is outlined before presenting the findings of interviews with built environment professionals in the London region.

\section{Interdisciplinarity}

Interdisciplinarity is seen as playing a crucial role in solving complex real world problems which cannot be adequately tackled by a single discipline. Since the Enlightenment, knowledge has become compartmentalized in 'a myriad of separate disciplines' (Ramadier, 2004 p. 423). This has resulted in most knowledge being currently organized, produced and applied in highly fragmented way, which limits our ability to address pressing global social and environmental problems (Clark \& Wallace, 2015). Interdisciplinarity draws on a number of disciplinary perspectives to provide practical solutions to problems and to develop a more coherent body of knowledge. Different degrees of collaboration and integration of knowledge are described by the 
terms, multidisciplinary, interdisciplinary and transdisciplinary. Multidisciplinary working tends to be used to describe teams where disciplines remain distinct, whereas interdisciplinarity and transdisciplinarity involve greater integration of knowledge. The boundary between interdisciplinary and transdisciplinarity is somewhat unclear (Aram, 2004). As the term, interdisciplinary, is much more frequently used by practitioners, this is the term used in this paper.

Planning is sometimes described as an interdisciplinary profession, because it draws on a number of more established disciplines (Davoudi \& Pendlebury, 2010). Over time it has developed from its technical, design-based origins. In some national contexts planning has moved almost exclusively into the realms of social science, whilst in others a strong design element remains (Frank et al, 2014). Whilst planning has established itself as an independent profession, the issues which it addresses are inherently interdisciplinary. Ellis et al (2008) point out that multidisciplinary working is particularly important to planners as the dominant paradigm in planning theory is one in which 'planners are portrayed as facilitators and mediators of different interests and expert opinions' (p. 75).

In the UK, policy makers as well as academics have increasingly acknowledged the benefits of interdisciplinary working across built environment disciplines. Due to concerns about the poor quality of the built environment and the need to promote sustainable development, UK Governments have initiated a number of reviews of the construction and development industries (Latham, 1994; The Construction Task Force, 1998; The Urban Task Force, 1999; Egan, 2004). Although these reviews had varying briefs, they all recognized the need for better integration of the processes and teams involved in the production of the built environment. A report commissioned by The Edge, a multidisciplinary think tank, considered that one of the key challenges facing the professions is that 'they tend to reinforce silos and to preserve hierarchies, when the requirement is (or may be) for increased integration of services for clients' (Morrell, 2015 , p. 25). It considered that the professional institutions had not kept up with the growth in multidisciplinary practices and the increasing number of practices that are companies with external ownership. The report recommended greater collaboration between the professional institutions. in order to improve their offer to society and to tackle issues such as climate change. It also recommended reviewing the siloed nature of the built environment's education system and the promotion of a cross-disciplinary approach to education. The Farrell Review of Architecture and the Built Environment (2015), an independent review, led by the architect Terry Farrell, aimed at influencing both government policy and industry practice, argued for a more proactive approach to planning, with an emphasis on place making: 'It is only through proactive planning that we can shape our built environment in a big-picture way to meet the social, environmental and economic needs of future generations' (The Farrell Review Team, 2015, p. 73). The Review recognized that this could only be achieved through architects, planners and urban designers working together and argued for the creation of 'an interdisciplinary workforce, able to break through the existing silos of working that are hindering our built environment today' (The Farrell Review Team, 2015, p. 64).

\section{Interdisciplinary Planning Education}

Rooij and Frank (2016) argue that planning education needs to prepare students for working in interdisciplinary environments. They note that there have been many 
innovations in interdisciplinary education such as joint foundation years and shared projects, but point out that these initiatives have not always been successful because interdisciplinary education is complex, resource intensive and require substantial institutional commitment to be sustained. McCarthy and Bagaeen (2014) reported on a number of interdisciplinary projects, which are elements of planning courses in the UK, but initiatives which embed the concept of interdisciplinarity across the whole programme are rarer. The Departments of Architecture and Engineering at the University of Cambridge offer a part-time masters course in Interdisciplinary Design for the Built Environment for early career professionals who already have a professional qualification (Jupp and Macmillan, 2010 and the University of the West of England offers a joint architecture and planning undergraduate (Manley \& Parnaby, 2000). The University of Westminster's new undergraduate degree, BA Designing Cities, is designed to educate design literate planners able to work effectively in an interdisciplinary context. We are aware from the experience of graduates of our masters planning course that the employment market for planners is buoyant and our initial dialogue with practitioners confirmed that planners who had additional skills in design would be particularly in demand, and this was echoed by the Farrell Review (2015), which highlighted the need for design literate planners.

\section{Graduate Employability}

Employability of graduates has become an increasing priority for universities (Holmes, 2013; Jackson, 2016; Blair \& Manda, 2016). Jackson (2016) argues that employability is about more than skills and knowledge, and that students are best prepared for practice through being encouraged to develop a develop a pre-professional identity through engagement in a community of practice. Planning is a vocational subject and planning education has always been intended to prepare students for professional practice. In the UK the Royal Town Planning Institute (RTPI) plays an important role in planning education. It sets learning outcomes for initial planning education, and partnership boards made up of practitioners and academics are responsible for accrediting and monitoring degrees (RTPI, 2012, 2015). However, this formal engagement with the profession is on its own not sufficient to ensure employability of graduates. The RTPI's own information on current practice is somewhat limited. The most recent survey of its membership, conducted in 2013, focussed on what services members wanted from the RTPI and only had a 25\% response rate (Koch and Harris, 2014). Due to this lack of detailed information about current planning practice and a desire for greater engagement with practitioners, we decided to undertake research on the nature of collaborative interdisciplinary planning and architectural practice in the London area to ensure that the graduates of our new degree programme would be well prepared for employment.

\section{The architectural and planning professions in the UK}

The research began with a review of relevant literature about the professions, current practice and interdisciplinary working. In the UK, professional bodies formally constituted themselves as membership organisations in the nineteenth century. Architects followed doctors, lawyers and engineers in establishing professional bodies; the Institute of British Architects was founded in 1834 and was granted a royal charter in 1837. By the early twentieth century the Royal Institute of British Architects (RIBA) had established a dominant position amongst practitioners. Since the Architects' 
Registration Act 1931, only those meeting agreed standards are legally permitted to call themselves architects (RIBA ARB Review Group, 2004). Planning is a newer profession. The Town Planning Institute was founded in 1914: membership was initially only open to existing members of the architectural, engineering and surveying professions, who had practical experience in town planning (Cherry, 1974). It was not until 1932 that direct entry to the profession via intermediate and final examinations was permitted. In 1947, the British Government set up a committee on the qualifications needed by planners. Its report placed less emphasis on design skills and more on social science (Schuster, 1950). Since the 1970s, urban design has been an emerging specialism at the interface between architecture and planning. Urban designers are not at present represented by a separate professional body.

In the period following the Second World War, when the state was active in postwar reconstruction and in building new housing and social infrastructure, planning was largely a public sector profession and a large proportion of the architectural profession was also directly employed by the state. During the 1980s and 1990s, the neo-liberal Conservative Governments in the UK had a considerable impact on both professions, due to policies promoting competition in the market for professional services and cutbacks in public expenditure. The Warne Report reviewed the protected title of architect and recommended its abolition (Warne, 1993). However, the RIBA, along with the National Consumer Council, successfully campaigned to maintain the protected title (Ball, 2009). Nonetheless, many architects question the relevance of the protected title in the context of the increasingly specialized division of labour (Ball, 2009; The Farrell Review Team, 2015).

In the 1970s, there was growing concern about the negative impact of the gap between the architectural and planning professions resulting in poor quality design of the built environment (Carmona, 1998). This led to a number of professionals, who were interested in promoting better interdisciplinary working, setting up the Urban Design Group (UDG) in 1978. In the UK, this is the principal group that focuses on the subject and on its website it states 'The UDG believes that urban design is not the job of any single profession so we welcome members from a broad range of backgrounds' (The Urban Design Group, n.d).

\section{Current practice and interdisciplinary working in the UK}

The literature about the current practice of built environment professionals indicates a shift towards private sector employment, changes in the size of firms and a growth in multidisciplinary firms. The most recent comprehensive survey of built environment professional services in the UK was undertaken by the Construction Industry Council (2007). It indicated that whilst most firms were small, 84\% employing fewer than 10 people, a small number of larger firms (2\% of the total) generated $78 \%$ of UK fee income. Connaughton and Meikle (2013) in their study of UK construction professional service firms over the previous 25 years highlighted the growth of larger, increasingly multidisciplinary practices. They identified the drivers of change being a decline in direct employment by the public sector and deregulation of the professions. They categorized the largest $20 \mathrm{UK}$ construction professional service firms in terms of their dominant discipline and found that, in 2011, ten were engineer led, three general surveyor led, three quantity surveyor led, one architect led and the remainder were either construction management or finance led. They noted that, between 1995 and 
2011, these firms had more than doubled their staff numbers and had increased the diversity of their services and their geographical scope. Connaughton et al (2015) noted that the largest firms in the sector had continued to increase their market share.

In contrast to the post-war years, the majority of architects in the UK now work in private practice, with a tiny proportion of the profession employed by the public sector. Brindley (2013) reported that, in 2013, only one in three local authorities employed architects. Whilst a growing number of planners work in the private sector, a significant proportion continues to be employed by the public sector. $50 \%$ of the respondents to the 2013 RTPI membership survey worked in local government (Thurman, 2013).

The RIBA 2012/13 survey of all registered practices showed that the majority of architectural practices (53\%) were small, with less than 10 members (Brindley, 2013). However, large firms, employing more than 50 people, whilst representing less than $5 \%$ of the total number of practices accounted for $40 \%$ of employment (Colander, 2014). Commentators noted the decline of middle-sized architectural practices (Brindley, 2013; Hopkirk, 2013).

The data available on planning practices is less comprehensive. The RTPI's Directory of Planning Consultants, which is available on the RTPI's website, provides details of firms which subscribe. Our analysis of practices in the London Region included in the directory shows a concentration of small practices (with less than 10 members), which account for $39 \%$ of the total, and large practices (with more than 50 members) accounting for $43 \%$ of the total.

Although interdisciplinary collaboration amongst built environment professions is widely advocated, there has been relatively little literature on interdisciplinary working in practice. Some of the professionals involved in teaching on the University of Cambridge's masters in Interdisciplinary Design for the Built Environment have reflected on their own practice. Price (2001), drawing on his own experience working as a structural engineer, described a range of different types of interdisciplinary collaboration. These included a project team involving different disciplines from different practices working in the same physical location on a large project, a large interdisciplinary practice organized into multidisciplinary teams and long-term partnership working between practices specialized in different disciplines. Price recognized the need for specialist knowledge and skills, but emphasized the importance of developing a common language for effective communication between experts from different fields. Ritchie (2001) stressed the importance of overcoming professional barriers between architects and engineers, arguing that the development of synthetic thinking requires a non-territorial attitude. He identified the crucial ingredients of collaborative working as listening to others, respect for individual skills, establishing a communality of aims and the development of mutual trust.

The American architect, Brause, (2017) recently published The Designer's Field Guide to Collaboration based on her interviews with architects discussing their collaboration with other design professionals such as landscape architects and engineers. She identifies some similar features of good practice to Price (2001) and Ritchie (2001) including good communication and respect for the skills of others. She also highlights the benefits of early design workshops to create shared visions for projects, giving and receiving constructive feedback, encouraging a culture of debate 
and challenge, working in close physical proximity to encourage a constant exchange of ideas, and collective reflection to build capacity to face future challenges.

\section{Interviews with practitioners}

The key primary research was a set of interviews carried out between May and September 2016. 24 interviews were conducted with professionals working in the London area to investigate the nature of collaborative practice, and to further scope out opportunities for future engagement with our new course. Interviews were initially arranged through existing contacts, particularly alumni. Further interviews were set up using a snowballing technique. The interviews were semi-structured and each interviewee was asked questions based on a standard schedule, which focussed on the themes identified in the literature review.

Interviews were conducted with architects, architect-planners, planners, landscape architects and transport planners working in a range of private and public sector practices varying in size and service offering. I8 interviews were conducted with private sector practices. The majority of the interviewees in the private sector worked in multidisciplinary practices, but some interviewees worked in smaller practices, which had well established cross-disciplinary links with other practices. The practices in which the private sector interviewees worked were categorized based on Connaughton and Meikle's (2013) classification of professional consultancies: seven were architect led, four planner led, two engineer led, three urban designer led, one surveyor led and one IT led. The majority of practices, 11 out of 18 , were large with more than 50 members; but the sample included three medium sized practices with between 10 and 50 members and four small practices with less than 10 members.

Three of the architect led firms interviewed have planning teams: two were created organically and one by a merger with an existing planning practice. In-house planning teams at each of these three firms offer a full range of planning services, including advice on planning applications and preparing master plans. All of these firms are large and only take on work in the UK. The fourth architect led large practice presents itself as architect-planners; $60 \%$ of its work includes master planning and urban design, and $50 \%$ of all of its work is located outside of the UK.

The planner led firms interviewed were comparatively smaller than the architecture practices. They typically offer a range of planning services (from project conception to planning permission and all stages in-between). The majority also offer urban design services. In comparison with the broader interdisciplinary service offered by other practice types, the planner led firms offer a relatively narrow range of services.

Two engineer led firms were interviewed. One is a very large international multidisciplinary practice of engineers, designers, and planners offering a wide range of services in the built environment disciplines. Its London office has a separate planning division and takes on work both in the UK and abroad. The other is a large practice offering engineering, urban design and conservation services focusing mainly on the UK market. Both of these firms have a very strong ethic of interdisciplinary working. 
Three firms described themselves as urban design practices. Two were established over 25 years ago and have played an important role in developing the agenda around urban design in the UK. The founders of both these practices were architect-planners. As well as urban design services, both are involved in developing regeneration strategies and stakeholder engagement, and one also provides planning advice. The third is a more recently formed small practice whose founder originally trained in architecture. This practice offers master planning, urban design and consultation services.

The IT led firm is a very large outsourcing company that provides a wide range of professional services. It is an international company with regional offices in the UK. The planning division, operates as a separate business within the larger organisation, but nonetheless aims to be part of a comprehensive one-stop-shop built environment service offered by the parent company.

Six interviews were conducted with architects, planners and architect-planners working in the public sector. The interviewees worked for three Local Authorities and two Development Corporations. The roles of interviewees varied and included planning policy, place making and design quality.

\section{Analysis of interviews}

The issues discussed in the interviews include the benefits of interdisciplinary working, work organisation, the ingredients to successful collaborative working and obstacles that needed to be overcome. All those interviewed stated that collaborative working with colleagues from different professional backgrounds was key to virtually all of their projects. The themes of best practice in collaborative working, which emerged from the analysis, relate to organisation, team building, communication and fostering a learning culture. The interviewees were also asked about how they saw the market for their services changing and the future of the professions.

There was a strong consensus on the value of collaborative working. Better quality design was seen as the foremost benefit. An architect who led a place making team in a local authority, when asked about the benefits of collaborative working, replied:

\footnotetext{
'Better built environment, better planning policy and better design. We started winning awards because of our multidisciplinary and collaborative way of working and again that feeds back into the process ... We are getting a higher calibre of recruits, because people want to work here, and developers are appointing better architects. It raises the game on everything.'
}

Another key benefit is a more streamlined service. The head of the planning team at an architect led practice explained that the planning team had been set up because: 'Schemes were going too far without getting the right planning advice, at the right stage.' The head of the London planning division of a large multidisciplinary practice reported that their clients wanted the one-stop-shop service, which they offered.

Most of the private sector practices involved in the research are organized in teams based on a particular discipline and operate a form of matrix management with multidisciplinary teams set up for particular projects. A few firms, particularly those with an urban design focus, have multidisciplinary teams. Similarly, two place-making teams in local authorities include staff from different disciplines. Some 
multidisciplinary project teams are made up exclusively of in-house staff, but others involve members of different practices. Many practices have developed long-term collaborative relationships with practices specialising in different disciplines. In some multidisciplinary practices, there is a policy of positively choosing to work with other practices, as this widens their experience.

Early involvement of different disciplines was seen as an important factor. A planning director in an architect led multidisciplinary practice explained: 'The critical thing is really involving all the disciplines early in the process, and giving them the opportunity to understand the direction of travel and also for those disciplines to feed into the design'. Good communication, particularly the ability to listen, was seen as crucial to building trust. It requires learning to understand the language and priorities of different disciplines. The head of planning in an architect led practice explained that communication had improved over time and that she now was able to speak more in 'a design language'. Building trust and developing mutual respect were widely seen as key ingredients in successful collaboration. The planning director of a large multidisciplinary practice elucidated:

\footnotetext{
'A potential obstacle is where you have different disciplines who work to their own agenda and are not actually listening to what other people are saying. I think if you work up trust with other consultants and team members over a period of time you get used to working together.'
}

Many interviewees highlighted the importance of developing shared objectives. A partner in an architect led multidisciplinary practice commented that: 'I think generally the design gets stronger the more specialist inputs you get, provided that there is a strong concept at the heart.' A partner in another architect led multidisciplinary practice described how on all their projects they developed a 'strong narrative for change'. He explained that this was a reiterative process involving not just the consultants, but all the stakeholders including politicians and the local community.

Many interviewees highlighted the role that design workshops play in effective collaborative working. A transport planner in an engineer led practice described how his practice organized multidisciplinary workshops:

'The face-to face interactive workshop at regular times throughout the project is usually a pretty successful way for mopping up a whole lot of issues and being able to resolve them rather than producing a plan, then getting a lot of input, when things are fixed.'

He also explained that the practice involves clients in these workshops, and that in a master planning project the client could be multi-headed, as several different organisations often were providing funding.

The main advantage of working in close physical proximity to professionals from other disciplines was seen by many as promoting effective communication. An architect-planner in an architect led practice explained:

\footnotetext{
'Physical remoteness is a barrier to interdisciplinary working. There are lots of digital tools that we are using. We have video conferencing, but critical things need to be face-to-face because it needs to be fast, and electronic things can't keep up with the reiteration and allow the decision to be made. You can share stuff about options (electronically), but when you actually want to say if it is $\mathrm{A}, \mathrm{B}$ or $\mathrm{C}$, it is easier to hammer that out in a shared room.'
} 
A planner in a multidisciplinary practice commented: 'Because we work at the same office there are opportunities to just sit down informally and bounce ideas off each other.' A number of the interviewees work in practices which provided shared space for socialising as a way to promote more informal communication between staff. Some practices regularly provide lunch for staff and this creates an opportunity to get to get know colleagues in other teams.

Many interviewees stressed the need to be open minded and flexible. An architectplanner in an urban design practice highlighted good practice as:

\footnotetext{
'Having an open mind so that you can listen to other points of view ... not being wedded to having one way of doing things and not saying this is our only solution ... having the flexibility to test out options is really important ... perhaps thinking the unthinkable in terms of what if we did it this way.'
}

A planner in an architect led practice considered that: 'Key to successful collaboration is the ability to accommodate feedback and to be flexible and not afraid of trying a different approach.' Whilst flexible thinking was recognized as important, interviewees also highlighted the need to respect professional boundaries and to be clear about the role of different team members. An architect-planner in an architect led practice commented: 'You need to have a team that have skills that are complementary so that people are not tripping over each other.'

The importance of the right input at the right time was widely emphasized. Whilst it is important to be clear about roles, in large projects these may need to change as projects evolve. A planner in an architect led practice, whose work included master planning, building design and interior design, pointed out that a different type of leadership is needed as projects move into different phases. He described how the leadership of a project for the expansion of an airport shifted from a partner with skills in strategic thinking and analysis of economic impacts, to a different partner when it was time to prepare a planning application.

The importance given to the role of project management varied considerably amongst the interviewees. Sometimes this is a separate role within the team; sometimes the design lead takes on this role. Whether teams include a dedicated project manager partly depends on the scale of the project but is also the result of the culture of the practice. Some firms put more emphasis on the process of project management. A transport planner in a large multinational engineer led firm emphasized the priority that they give to project management:

\footnotetext{
'Another aspect of our practice is that we do a lot of project planning, so before the start of a project we plan out roles and responsibilities and who is doing what. The project manager will always be someone within the team. Our staff, when they reach that level, are all trained as project managers and accredited within the business.'
}

Many of the practices have regular in-house seminars, where participants share knowledge on a particular topic and discuss projects. On some occasions, these seminars also involve external consultants with whom they regularly work. The two engineer led practices put considerable emphasis on learning from project to project. One holds charrettes every two to three weeks where a member of staff presents a project or discusses a technical issue. A transport engineer from this practice 
commented: 'It is quite a challenge for people. I have been through a couple where I have been challenged quite a lot. You end up in a different place and see the project differently.' However, differences in the ways in which architects and planners discuss their work can initially be a barrier to learning across the practice. Project crits are a deeply embedded part of the culture of architectural schools, which continue in practice. A planner working in an architect led practice explained that planners could feel quite alienated and find the process overly subjective, but over time the planners in this practice have gradually come to understand the skills that architects bring and their skills have become valued by the architects.

A number of themes emerged around how the interviewees saw the market for their services changing and how their practices were positioning themselves to be able to adapt to change. In some practices, the staff are increasingly specialized. A partner of a large architect led multidisciplinary practice explained that most of their projects involve mixed uses. They have architects who specialized in retail, commercial and residential projects, and having this mix of skills enables them to respond flexibly if the market shifts, for example, from residentially led projects to commercially led projects. Other interviewees noted an increasing demand for specialist planning advice: in the past architects or surveyors would have given planning advice, but clients increasingly value specialist advice. However, others highlighted that, particularly at a more senior level, there is an emphasis on more generic skills such as an understanding of governance issues. A transport planner in a large international multidisciplinary practice explained that:

\footnotetext{
'In the last 2-3 years we have definitely had much more focus on cities. This is linked to city mayors becoming more prominent in the UK and around the world. Cities are drivers of development and the whole urbanisation process and more sustainable solutions. We have focussed our business more on cities than countries and try to work with city mayors as they have more power to change things.'
}

Most practices, as well as aiming to work on a mix of project types, aim to have a mixed client base in order to be better able to respond to changing demand. For some, this means having a balance of domestic and international clients, whilst for others it means a balance of public and private sector clients. The referendum on the UK's membership of the European Union occurred during the period in which the interviews were being conducted. The initial view of the impact of the vote for Brexit was that it was having a mixed effect. As a result of the fall in the value of sterling, foreign investors were keen to invest, as their money would go further. Similarly, tourism related projects were seen as good investments. However, other sectors, such as highend residential, were adversely affected and projects were being put on hold.

There were mixed views about the relevance of the professional bodies to practice. Whilst their role in education was widely recognized, there was concern that they were perpetuating a silo mentality. Quite a number of the interviewees expressed a frustration with the professional bodies for not adapting to the pace of change and not tackling the big issues. Some interviewees felt that they would have a more powerful voice if they were part of a broader built environment professional group. One architect-planner commented: 'It is critical that the professions get aligned and talk about the issues facing cities.'

\section{Conclusions}


This research indicates a strong commitment to interdisciplinary working amongst a range of built environment professionals working in the London area. There was a consensus amongst the interviewees that collaborative interdisciplinary working produced better quality outcomes. Early involvement of all the disciplines was recognized as important to successful collaboration. Good communication skills, particularly listening skills, were seen as key to building trust and mutual respect, and to developing shared objectives. Design workshops at an early stage of a project played an important role in developing shared visions. Face-to-face meetings were widely seen as crucial for exploring design options, and co-location of professionals from different disciplines was seen as encouraging informal communication that facilitate more effective collaboration. Flexibility and the ability to respond to feedback were identified as key ingredients in achieving the best overall solutions. Whilst flexibility was recognized as important, the need to respect professional boundaries and to be clear about the role of team members was also highlighted. The features of successful collaborative working identified in this research strongly echo those found by Brause (2017) in her research on architects and collaborative working in the USA. These research findings show the relevance of these features to a broader range of professional disciplines in a different national context.

The research findings suggest that larger multidisciplinary practices are better able to realize the advantages of co-location of different professional disciplines and to encourage more effective collaborative interdisciplinary working by promoting a learning culture through shared workshops, seminars and training. However, smaller practices can realize some of these benefits by sharing premises with professionals from other disciplines and by holding joint seminars and other events. Although few architects are now employed in the public sector in the UK, the research indicated that, in the authorities and agencies where they were employed, they were able to make a significant contribution to the quality of the built environment through collaboration with planning colleagues.

Whilst the professionals who participated in this research were committed to collaborative interdisciplinary working, it was clear that there remain obstacles to it becoming mainstream practice. There is still a tendency for professionals to work to the priorities of their own discipline and not to appreciate fully the benefits that closer working with professionals from other disciplines can bring. Some of those interviewed expressed frustration that the professional bodies of the different disciplines sometimes reinforced a silo mentality and failed to adequately address the bigger challenges facing society. These views support the case for closer cooperation between professional bodies advocated by the Edge (Morrell, 2015). Education was highlighted as having a crucial role to play in breaking down interdisciplinary boundaries. This will require professional bodies to be more flexible in how they approach the accreditation of courses for entry into their professions.

The research findings confirm the need for education to prepare students for working in an interdisciplinary environment. The findings will make a significant contribution to the further development of our new degree course and help to give students the right knowledge and skills to ensure their future employability in interdisciplinary working environments. The body of knowledge developed in the research will inform the content of many of the modules in the programme. The research will also encourage a 
deeper engagement with practitioners and help the course embed within a wider community of practice, which will in turn help students develop a pre-professional identity (as advocated by Jackson, 2016). The interviewees were enthusiastic about the focus of the course and many offered to be involved with the course in a range of ways, including giving lectures to students, hosting visits by students to their projects, acting as an external examiner, attending crits of student projects and offering work placements to students. A number of the interviewees have already given presentations to students on their work, which were really useful, as they gave students at the start of their studies some ideas about the kind of projects, which they might be able to work on later in their careers.

This research also makes a contribution to filling the gap in the literature on interdisciplinary working in practice. However, it was exploratory and small in scale, so there is therefore considerable potential for further research on the subject. Given that our degree programme is internationally focussed, research on collaborative architectural and planning interdisciplinary practice in other national contexts would be of particular interest.

\section{Acknowledgements}

The author would like to thank the Quintin Hogg Trust, which provided financial support for the research, all the interviewees and Kerry Bobbins, who assisted with the research.

\section{References}

Aram, J. D. (2004) Concepts of interdisciplinarity: Configurations of knowledge and action, Human Relations, 57(4), pp. 379-412.

Ball, C. (2009) A Report for the RIBA on the Registration and Regulation of Architects. Available at https://www.architecture.com/Files/RIBAHoldings/Communications/Press/RulesA ndRegulations.pdf (accessed 20 June 2016).

Blair, N. \& Manda, M. (2016) A partnership-based model for embedding employablity in urban planning education, Urban Planning and Transport Research, 4(1), pp. 46-63.

Brause, K. (2017) The Designer's Field Guide to Collaboration (New York and London: Routledge).

Brindley, R. (2013) Is architecture a tale of two professions? Building Design. Available at http://www.bdonline.co.uk/business/is-architecture-a-tale-of-twoprofessions?/5053423.article (accessed 20 June 2016).

Carmona, M. (1998) Design Control - Bridging the Professional Divide, Part 1: A New Framework, Journal of Urban Design, 3(2), pp. 175 -200.

Cherry, G.E. (1974) The evolution of British town planning: a history of town planning in the United Kingdom during the 20th century and of the Royal Town Planning Institute, 1914-74 (Leighton Buzzard: L. Hill).

Clark, S.G., \& Wallace, R.L. (2015) Integration and interdisciplinarity: concepts, frameworks, and education, Policy Sci, 48, pp. 233-255.

Colander (2014) RIBA Business Benchmarking: 2013/14 Executive summary. Available at https://www.architecture.com/Files/RIBAProfessionalServices/Practice/Benchmar 
king/RIBABusinessBenchmarkingExecutiveSummary2013-14.pdf (accessed 19 July 2016).

Connaughton, J. \& Meikle, J. (2013) The changing nature of UK construction professional service firms, Building Research \& Information, 41 (1), pp. 95-109.

Connaughton, J. Miekle, J.\& Teerikangas, S. (2015) Mergers, acquisitions and the evolution of construction professional services firms, Construction Management and Economics, 33 (2), pp.146-159.

Davoudi, S. \& Pendlebury, J. (2010) The evolution of planning as an academic discipline, Town Planning Review, 81(6), pp. 613-645.

Ellis, G., Morrison, S., \& Purdy, J. (2008) A New Concept of Interprofessional Education in Planning Programmes: Reflections on Healthy Urban Planning Project, Journal of Education in the Built Environment, 3(2), pp. 75-93.

Egan, J. (2004) Skills for Sustainable Communities, London: Office of Deputy Prime Minister.

Frank, A. I., Mironowicz, I., Lourenço, J., Franchini, T., Ache, P., Finka, M., Scholl, B. \& Grams, A. (2014) Educating Planners in Europe: A review of $21^{\text {st }}$ century study programmes, Progress in Planning, 91, pp. 30-94.

Holmes, L. (2013) Competing perspectives on graduate employablity: possession, position or process? Studies in Higher Education, 38(4). pp. 538-554.

Hopkirk, E. (2013) RIBA survey finds 'split profession', Building Design. Available from http://www.bdonline.co.uk/news/riba-survey-finds-splitprofession/5053383.article (accessed 20 June 2016).

Jackson, D. (2016) Re-conceptualising graduate employablity: the importance of preprofessional identity, Higher Education Research and Development, 35(5), pp. 925-939.

Jupp, J. \& Macmillan, S. (2010) Promoting teamwork and sustainable design, The Structural Engineer, 88(2). Available at https://www.istructe.org/downloads/education/idbe/idbe-tse-feature.pdf (accessed 19 July 2016).

Koch, M. \& Harris (2014) RTPI Membership Survey 2013 - Summary results. London: RTPI.

Latham, M. (1994) Constructing the Team. Final Report of the Government/Industry Review of Procurement and Contractual Arrangements in the UK Construction Industry, London: HMSO.

Manley, S. \& Parnaby, R. (2000) The Return of the Architect-Planner? Planning Practice and Research 15(3), pp. 269-277.

McCarthy, J. \& Bagaeen, S. (2014) Sharing Good Practice in Planning Education, York and London: The Higher Education Academy and the RTPI.

Morrell, P. (2015) Collaboration for Change: The Edge Commission report on the future of the professions. Available from http://www.edgedebate.com/wpcontent/uploads/2015/05/150415_collaborationforchange_book.pdf (accessed 19 July 2016).

Price, S. (2001) Different models of interdisciplinary working, in: R. Spence, S. Macmillan \& P. Kirby (Eds) Interdisciplinary Design in Practice (London: Thomas Telford).

Ramadier, T. (2004) Transdisciplinarity and its challenges: the case of urban studies, Futures, 36, pp. 423-439.

RIBA ARB Review Group (2004) Historical Background to Architects' Registration. Available at 
https://www.architecture.com/Files/RIBAHoldings/Communications/Press/PressR elease/2004/ARBReporthistory.pdf (accessed 26 August 2016).

Ritchie, I. (2001) Synthetic thinking between engineers, architects and designers, in: R. Spence, R., S. Macmillan. \& P. Kirby, (Eds) Interdisciplinary Design in Practice (London: Thomas Telford).

Rooij, R. \& Frank, A. (2016) Educating spatial planners for the age of co-creation: the need to risk community, science and practice involvement in planning programmes and curricula, Planning Practice \& Research, 31(5), pp. 473-485.

RTPI (2012) Policy Statement for Initial Planning Education, London: RTPI.

RTPI (2015) Partnership Board Guide for Participants, London: RTPI.

Schuster, G. (1950) Report of the Committee on Qualifications of Planners, London: HMSO.

The Construction Industry Council (2007) Survey of UK Construction Professional Services, 2005/6, London: Construction Industry Council.

The Construction Task Force (1998) Rethinking Construction, London: HMSO.

The Farrell Review Team (2015) The Farrell review of architecture and the built environment: Our future in place, London: Farrells. Available at http://www.farrellreview.co.uk/downloads/ (accessed 25 May 2016).

The Urban Design Group (n.d) About the Urban Design Group. Available at http://www.udg.org.uk/about (accessed 9 August 2016).

The Urban Task Force (1999) Towards an Urban Renaissance, London: Spon.

Thurman, M. (2013) Membership Survey: Research report for the Royal Town Planning Institute. Available at http://www.rtpi.org.uk/knowledge/research/projects/membership-survey/ (accessed 19 July 2016).

Warne, E.J.D. (1993) Review of the Architects (Registration) Acts 1931-1969, London: HMSO. 